\title{
Controlled Growth of nano-Hydroxyapatite on Stilbite: Defluoridation Performance
}

Taju Sani, a,b Luis Gómez-Hortigüela, ${ }^{c}$ Álvaro Mayoral, ${ }^{\mathrm{d}}$ Yonas Chebude, ${ }^{\mathrm{a}}$ Joaquín PérezPariente, ${ }^{\mathrm{c}}$ Isabel Díaz,

${ }^{a}$ Chemistry Department, Addis Ababa University, P. O. Box 1176, Addis Ababa, Ethiopia

${ }^{b}$ Chemistry Department, Dilla University, P.O.Box419, Dilla, Ethiopia

${ }^{\mathrm{c}}$ Instituto de Catálisis y Petroleoquímica, CSIC, c/Marie Curie 2, 28049 Madrid, Spain

${ }^{\mathrm{d}}$ Advanced Microscopy Laboratory (LMA), Nanoscience Institute of Aragon (INA), University of

Zaragoza, Zaragoza, Spain 


\begin{abstract}
In Ethiopia, fluoride-contaminated groundwater used for drinking has become a matter of great concern, particularly in the Rift Valley region, due to its serious health hazard (fluorosis). In the present work, we present a systematic study related to the optimization of the synthesis of a composite material having a high defluoridation capacity, consisting of nanohydroxyapatite crystals growth on the external surface of a natural Stilbite zeolite (nHAST) of sizes between 74 and $105 \mu \mathrm{m}$. In order to control the growth of significantly small crystals of hydroxyapatite with higher fluoride removal capacity, the most important synthesis parameters, crystallization $\mathrm{pH}$ and crystallization time, have been carefully optimized. The obtained materials have been characterized by X-Ray Diffraction, Elemental Analysis, Thermogravimetric Analysis, Infrared Spectroscopy, ${ }^{31} \mathrm{P}$ Nuclear Magnetic Resonance, and Transmission Electron Microscopy; in addition, the defluoridation capacity of the materials has been determined. Interestingly, unlike most adsorbents, nHAST-144h (prepared after 144 hours of crystallization) shows significantly high fluoride-removal efficiency in a wide range of $\mathrm{pH}$ with maximum F-removal of $86 \%$ and minimum of $79 \%$ fluoride removals at $\mathrm{pH} 3$ and 10, respectively. Besides, nHAST-144h adsorbent maintains its high defluoridation capacity in the presence of other ions, in particular chloride, sulfate and bicarbonate. In a real situation, nHAST-144h was found to be efficient as well; from real groundwater from the Ethiopian Rift Valley, with a fluoride concentration of 8.2 $\mathrm{mg} / \mathrm{L}$ and a dose of $10 \mathrm{~g} / \mathrm{L}$, nHAST-144h reduced the fluoride concentration down to $1.40 \mathrm{mg} / \mathrm{L}$, below the limit established by World Health Organization (WHO).
\end{abstract}

\title{
Keywords
}

Fluoride; Fluorosis; Defluoridation; Zeolites; nano-Hydroxyapatite 


\section{Introduction}

Fluoride at a fairly low level is beneficial to the human body for the calcification of dental enamel, prevention of dental decay and maintenance of healthy bones. However, excessive fluoride intake is harmful for human health, leading to dental and skeletal fluorosis, lesion of endocrine glands, thyroid, liver and other organs [1-3]. According to World Health Organization (WHO) guidelines, the acceptable fluoride concentration in drinking water must be in the range between 0.5 to $1.5 \mathrm{mg} / \mathrm{L}$ [4]. Despite its frequent high fluoride content, groundwater is widely distributed, and a significantly large number of population, more than 260 million all over the world, consume drinking water with a fluoride concentration higher than $1.0 \mathrm{mg} / \mathrm{L}$. The majority of these people live in tropical regions, fourteen countries in Africa, eight in Asia, and six in the Americas [5, 6], and many of them are confronted with problems due to endemic fluorosis, either dental or skeletal. For instance, in the Rift Valley (Ethiopia) as well as in the North of Mexico, the fluoride content may reach as much as $36 \mathrm{mg} / \mathrm{L}[7,8]$ and $8 \mathrm{mg} / \mathrm{L}[9,10]$, respectively. Thus, the problem is severe and needs immediate solution.

For many years [11], a large number of adsorbent materials have been tested in fluoride removal. Among them, hydroxyapatite (HAp), one of the most extensively investigated defluoridating adsorbents, is of great importance because of the similarity in chemical composition with human bone and the potential for fluoride retention [12]. Many researchers studied HAp-based adsorbents and indicated their potential for fluoride-removal [13-16]. Although HAp has shown an excellent potential towards the retention of fluoride from water, current research is applied in an attempt to further enhance its fluoride-removal capacity through the production of nanosized HAp materials, which in recent years have gained much attention for their unique properties. In this context, a significant number of nano-hydroxyapatite (nHAp) adsorbents have been 
synthesized and studied [17-21]. In fact, these nanosized materials showed a much higher defluoridation capacity because of the small crystal size, and consequently the reduction of problems related to diffusion limitations of the ions in larger crystals. However, the potential application of these materials in the field is not easily achievable, due to the cost associated with their production and significant pressure drops during filtration owing to the small particle size. To overcome such permeability problems and at the same time utilize the advantages of nHAp, it is essential to prepare adsorbents based on nHAp in a usable form by combining them with other high-surface materials [22-24], on which the HAp nanoparticles are supported. By having the HAp nanoparticles supported on the external surface of a material with a large particle size, it would be possible to avoid pressure drops associated with the nanosize of nHAp, as well as to prevent the potential toxicity typical of nanoparticles and possible sintering (and loss of efficiency) during defluoridation treatments. In our previous studies, we have reported the potential use of nano-hydroxyapatite (nHAp) crystals grown on the surface of natural stilbite (STI) from Ethiopia as $\mathrm{F}^{-}$adsorbents (nHAST) [25]. In the current work, different synthesis conditions have been systematically studied aiming to yield an optimum synthesis method that may allow for a scale up synthesis. Among the most relevant parameters, the synthesis $\mathrm{pH}$ is a crucial factor in the formation nano hydroxiapatite with significantly higher efficiency. Therefore, this manuscript includes the effect of the growth of nHAST without $\mathrm{pH}$ adjustment (autogenous $\mathrm{pH}$ value of 8 ) and crystallization at room temperature, unlike the common precipitation methods of HAp which in most cases is carried out at basic $\mathrm{pH}(>9)$ together with high temperature conditions. The effect of several defluoridation-process parameters, water $\mathrm{pH}$, presence of co-ions, contact time, adsorbent dose and initial fluoride concentration, on the defluoridation performance of nHAST composites has been studied. Finally, equivalent nHAST 
composites showing the same properties have been synthesized using different natural stilbite samples from alternative deposits located in Northern Ethiopia.

\section{Experimental Part}

\subsection{Adsorbent preparation}

Natural stilbite (zeolite) samples were provided by the School of Earth Sciences, Addis Ababa University. The main stilbite sample used in this work was collected from the Hashenge basalt formation in the Tigrai region, and the rest of the samples were collected in the localities of Korem and Maychew in the same region. The nHAST composite is prepared as follows: $2 \mathrm{~g}$ of STI zeolite powder of average particle size between 74 and $105 \mu \mathrm{m}$ was mixed with $30 \mathrm{ml}$ of 1 $\mathrm{M}\left(\mathrm{NH}_{4}\right)_{2} \mathrm{HPO}_{4}$ and stirred for $2 \mathrm{~h}$. The solution $\mathrm{pH}$ was then adjusted at different values (from 7 to 10), either with $0.1 \mathrm{M} \mathrm{HCl}$ or $0.1 \mathrm{M} \mathrm{NaOH}$. Optimization of the crystallization $\mathrm{pH}$ (from 7 to 10) was performed at a fixed crystallization time of 19 hours, and optimization of the crystallization time was studied for periods ranging from 2 to 144 hours at the optimized crystallization $\mathrm{pH}$; both crystallization studies were performed at room temperature conditions. The adsorbent was filtered, washed and dried in open air at room temperature overnight.

\subsection{Characterization}

Powder X-Ray Diffraction (XRD) patterns were collected with an X'pert Pro PANalytical diffractometer equipped with an X'celerator detector using a $\mathrm{Cu} \mathrm{K}_{\alpha}$ radiation and Ni filter, which has a wavelength of $1.54056 \AA$. The stilbite phase identification was done using the ICSD database for X'Pert Highscore Plus with Reference code 00-044-1479. The chemical inorganic composition has been determined by Inductively Coupled Plasma Optical Emission 
Spectrometry (ICP-OES, Optima 3300 DV model). The content of HAp (wt \%) in the nHAST composite material is calculated from the P content obtained from this elemental analysis (wt \%), according to eq. 1 .

$$
\text { HApwt } \%=\mathrm{P}_{\text {wt }} \%_{(\mathrm{ICP})} \mathrm{x} \quad \frac{502}{93} \quad \text { Equation } 1
$$

where 502 is the total molecular mass of $\mathrm{HAp},\left(\mathrm{Ca}_{5}\left(\mathrm{PO}_{4}\right)_{3} \mathrm{OH}\right)$ and 93 is the molecular mass of $\mathrm{P}$ in HAp.

Thermogravimetric (TGA) analyses were performed on a thermogravimetric analyzer PERKIN ELMER TGA7; samples were heated at a rate of $20^{\circ} \mathrm{C} \cdot \min ^{-1}$ up to a maximum temperature of $900^{\circ} \mathrm{C}$ under air flow. Infrared measurements were carried out using an Attenuated Total Reflectance spectrophotometer (ATR, PIKETECHNOLOGIES) in the range of 500-4000 $\mathrm{cm}^{-1}$, using quartz as detector. ${ }^{31} \mathrm{P}$ MAS-NMR was used to confirm the presence of HAp in these adsorbents; the spectra were recorded at room temperature using a Bruker AV-400-WB spectrometer and a recycle delay of $20 \mathrm{~s}$, while spinning the samples at $162 \mathrm{MHz}$. Furthermore, in order to study the atomic structure and the nature of the composite, Transmission Electron Microscopy was applied. Scanning Transmission Electron Microscopy (STEM) was chosen, as it is less damaging to electron-beam sensitive materials. The observations were performed on selected nHAST composite samples, prepared with crystallization times of 19 and 144 hours. STEM studies were performed with a spherical aberration corrected FEI Titan XFEG, which was used at $300 \mathrm{kV}$, equipped with a corrector for the electron probe allowing a maximum resolution of $0.8 \AA$; the microscope was also equipped with an EDS detector (Energy Dispersive Spectroscopy) and a Gatan Tridiem energy filter for EELS (Electron Energy Loss Spectroscopy) 
measurements. Prior to observations, the samples were crushed, dispersed in ethanol or acetone and placed onto a holey carbon copper micro grid. The point of zero charge (PZC) was measured by potentiometric mass titrations technique [26, 27], using 665 Dosimat (Metrohm, Switzerland) machine. The $\mathrm{pH}$ was measured using a digital $\mathrm{pH}$ meter standardized by buffers (WTW Inolab pH/ION Level 2, Germany).

\subsection{Fluoride-removal experiments}

Fluoride-containing solutions of two initial $F$ concentrations $\left(C_{o}\right), 5$ and $10 \mathrm{mg} / \mathrm{L}$, have been prepared from sodium fluoride ( $\mathrm{NaF}$, Sigma-Aldrich), in accordance with the most frequently reported values from real polluted drinking water samples, from 1.5 up to $11.6 \mathrm{mg} / \mathrm{L}$, in the Rift Valley region in Ethiopia [28]. In particular cases, different initial fluoride concentrations and adsorbent doses were studied. Defluoridation experiments were carried out at room temperature $\left(23 \pm 2{ }^{\circ} \mathrm{C}\right)$, with a contact time of $20 \mathrm{~h}$ under continuous agitation. The concentration of fluoride in the initial solution and after equilibrium upon the addition of the adsorbent was measured by the Ion Selective Electrode technique with a pH \& Ion-meter GLP 22 CRYSON, after addition of a total ion strength adjustment buffer (TISAB III, CRISON). All experiments were repeated in order to test the reproducibility and mean values are reported. The adsorption efficiency $\left(\mathrm{Q}_{\mathrm{t}}\right)$, and defluoridation capacity $\left(\mathrm{Q}_{\mathrm{e}}\right)$ were calculated following eq. 2 and 3:

$$
\begin{array}{ll}
\mathrm{Q}_{\mathrm{t}} \frac{\mathrm{C}_{\mathrm{o}}-\mathrm{C}_{\mathrm{t}}}{\mathrm{C}_{\mathrm{o}}} \times 100 & \text { Equation 2 } \\
\mathrm{Q}_{\mathrm{e}}=\frac{\mathrm{C}_{\mathrm{o}}-\mathrm{C}_{\mathrm{t}}}{\text { dose }} & \text { Equation 3 }
\end{array}
$$


where $\mathrm{C}_{\mathrm{o}}$ is the initial $\mathrm{F}^{-}$concentration, $\mathrm{C}_{\mathrm{t}}$ is the equilibrium $\mathrm{F}^{-}$concentration (both in $\mathrm{mgF} / \mathrm{L}$ ), and the dose is expressed in $\mathrm{g} / \mathrm{L}$.

In this study, apart from the total defluoridation capacity $\left(Q_{e}\right)$, which is referred to the total mass of the composite material, including the zeolite and the HAp ( calculated following eq. 3), the intrinsic capacity of HAp $\left(\mathrm{Q}_{\mathrm{e}}(\mathrm{HAp})\right.$ ), which is referred only to the percentage of HAp in the composite material, was used to describe the relative activity of the adsorbent material with respect to the amount of HAp, and was calculated following eq. 4:

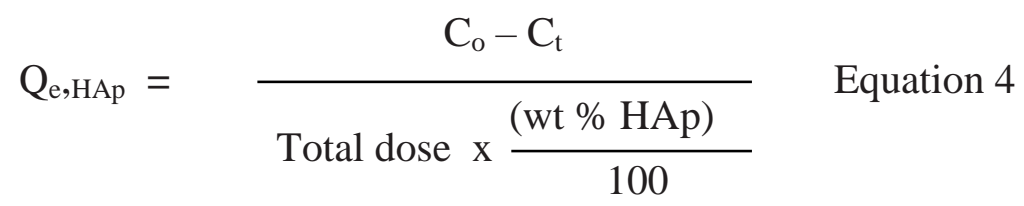

Studies were also conducted in order to investigate the effect of process parameters during fluoride adsorption by nHAST. The effect of the adsorbent dose on fluoride removal was studied by varying the dose from 4 to $12 \mathrm{~g} / \mathrm{L}$. The effect of the initial fluoride concentration and contact time on nHAST composite was investigated by varying initial fluoride concentrations and contact time from 5 to $200 \mathrm{mg} / \mathrm{L}$ and from 0 to 28 hours, respectively. The effect of the water $\mathrm{pH}$ on the adsorption of fluoride on nHAST adsorbent was studied by varying the water $\mathrm{pH}$ from 3 to 10 ; again the $\mathrm{pH}$ was adjusted to the desired value either with $0.1 \mathrm{M} \mathrm{NaOH}$ or $0.1 \mathrm{M} \mathrm{HCl}$. The effect of co-existing anions $\left(\mathrm{HCO}_{3}{ }^{-}, \mathrm{SO}_{4}{ }^{2-}\right.$ and $\left.\mathrm{Cl}^{-}\right)$on fluoride adsorption by nHAST composite was also studied in the presence of anions that commonly exist in groundwater [29]. A series of solutions with different concentrations of each target anion $(0-500 \mathrm{mg} / \mathrm{L})$ was prepared by dissolving the sodium salts of the respective anions in de-ionized water containing the desired concentration of fluoride. 


\section{Results and Discussion}

The synthesis of the composite material based on the growth of nano hydroxiapatite on the surface of natural stilbite involves an initial exchange of $\mathrm{NH}_{4}{ }^{+}$present in the synthesis solution by the exchangeable $\mathrm{Ca}^{2+}$ cations from the STI zeolite; these released $\mathrm{Ca}^{2+}$ ions then crystallize as HAp nanoparticles on the external surface of the zeolite in the presence of $\mathrm{PO}_{4}{ }^{3-}$ from the synthesis solution at a given $\mathrm{pH}$. In this cation exchange process the slow release of $\mathrm{Ca}^{2+}$ ions acts as determing factor for the nucelation of hydroxyapatite, therefore time, crystallization time

has to be studied in order to reach and optimum exchange. Furthermore, the $\mathrm{pH}$ of the $\mathrm{PO}_{4}{ }^{3-}$ from solution will determine the growth of the HAp nanoparticles. Therefore, different synthesis conditions have been systematically studied aiming to yield an optimum equilibrium between the nucleation and the growth of the aimed nanohydroxyapatite.

The particle size of the natural zeolite used here varied in three main regimes: smaller than 74 $\mu \mathrm{m}$, within 74 and $105 \mu \mathrm{m}$ and larger than $125 \mu \mathrm{m}$. Crystals at the larger size regime did not show HAp crystallization while the smallest ones were too difficult to handle due to turbidity effects they created in the suspensions. The sizes of the stilbite crystals used throughout this work were in the range from 74 to $105 \mu \mathrm{m}$.

\subsection{Optimization of Crystallization pH}

The effect of crystallization $\mathrm{pH}$ on the growth and amount of HAp crystallized on the STI surface was initially investigated by XRD (Figure 1). As can be clearly observed, all the nHAST composite samples synthesized from different crystallization pHs as well as the original STI zeolite showed very similar X ray diffraction patterns. The main peaks of the STI framework are 
clearly observed in all the materials, confirming the stability of the zeolite under the synthesis conditions; however, no XRD reflections due to the growth of nHAp could be appreciated. The quantitative chemical compositions of the nHAST samples synthesized from different crystallization $\mathrm{pHs}$ were determined by ICP and are presented in Table 1. As observed, ICP analysis detected a constant amount of $\mathrm{Ca}^{2+}$ on the different materials. No $\mathrm{P}$ was detected at all in the original STI, while a constant amount of $\mathrm{P}$ was also observed in the nHAST composite samples. Thus, the wt \% of HAp grown on the STI surface (as calculated from the content of P determined by ICP, eq. 1) is also constant, irrespective of the crystallization $\mathrm{pH}$.

Batch-mode defluoridation tests were used to analyze the fluoride-removal capacity of nHAST composite samples at two initial fluoride concentrations: 5 (Figure 2A) and $10 \mathrm{mg} / \mathrm{L}$ (Figure 2B), using $10 \mathrm{~g} / \mathrm{L}$ of adsorbent dosage for a contact time of 20 hours at room temperature. Figure 2 plots the variations in $\mathrm{F}^{-}$removal capacity among the samples as a function of the crystallization $\mathrm{pH}$. The defluoridation capacities of nHAST samples synthesized with a crystallization $\mathrm{pH}$ of 7.0-7.5 were slightly lower. Similarly, the nHAST samples prepared at basic crystallization $\mathrm{pH}$ conditions ( $\mathrm{pHs}$ of 8.5, 9 and 10) showed lower defluoridation capacities (in the same order), which might be associated to the formation of larger HAp particles at basic crystallization $\mathrm{pH}$ conditions. On the other hand, very efficient (and probably smaller) HAp particles are formed at an intermediate $\mathrm{pH}$ of 8 , yielding the highest defluoridation capacity so far. Interestingly, at this $\mathrm{pH}$ the nHAST composite shows about 89 and $67 \%$ of $\mathrm{F}^{-}$removal efficiency, from initial concentrations of 5 and $10 \mathrm{mgF}^{-} / \mathrm{L}$, respectively; these capacities were notably higher than that of nHAST obtained at a $\mathrm{pH}$ of 9 , with a removal efficiency of about 76 and $61 \%$, respectively, from water with the same initial fluoride concentrations (Figure 2). Therefore, the best 
performing (optimized) crystallization $\mathrm{pH}$ for further preparation of nHAST composites was considered as the autogenous $\mathrm{pH}$ of 8 , and hence not involving additional chemicals.

\subsection{Optimization of Crystallization Time}

In order to investigate the effect of the crystallization time on the defluoridation performance by nHAST composites, a series of samples were prepared at various crystallization times ranging from 2 to 144 hours, at the optimized autogenous $\mathrm{pH}$ of 8 . In this case, a close inspection of the diffraction patterns showed slight variations in the region between 23 and $25^{\circ} 2 \theta$ (Figure 3). In this region, the initial STI mineral showed three clearly distinguishable peaks characteristic of monoclinic stilbite, while the nHAST composite samples showed a single diffraction (marked by a downward arrow in Figure 3), evidencing a progressive change of the space group of STI to orthorhombic $[30,31]$. This is caused by the exchange of $\mathrm{Ca}^{2+}$ and $\mathrm{Na}^{+}$of the original stilbite by $\mathrm{NH}_{4}{ }^{+}$ions during the preparation of the composites. The identification of the characteristic crystalline peaks that confirm the formation of HAp on the STI surface by XRD was again not possible, probably due to the low concentration of HAp in the composite, its small (nanometric) crystal size and/or the overlapping with the more abundant and intense STI zeolite diffractions.

Figure 4 shows the thermogravimetric analysis results of the STI zeolite support and of nHAST composite samples. In the temperature region up to $350{ }^{\circ} \mathrm{C}$, several differentiated weight losses can be observed in both the STI and the nHAST composite samples. In STI, a first weight loss at temperatures below $130{ }^{\circ} \mathrm{C}$ is assigned to loosely bound water, while a second strong weight losses with maximum desorption rates at around $170{ }^{\circ} \mathrm{C}$ and at $260{ }^{\circ} \mathrm{C}$ are due to the desorption of strongly retained water molecules within the STI framework by coordination with exchangeable $\mathrm{Ca}^{2+}$ ions. A progressive shift of the maximum desorption rate of these weight 
losses associated to dehydration to lower temperatures can be clearly observed in the case of nHAST samples, possibly due to the weaker interaction of water molecules with monovalent $\mathrm{NH}_{4}{ }^{+}$ions exchanged for $\mathrm{Ca}^{2+}$ ions, as compared to the stronger interaction with divalent $\mathrm{Ca}^{2+}$ ions in the original STI sample. Indeed, this decrease to lower temperatures is gradual upon an increase of the crystallization time. Hence, these shifts to lower temperatures are an indication of the progressive exchange of the more-interacting (with water) $\mathrm{Ca}^{2+}$ divalent cations by the lessinteracting monovalent $\mathrm{NH}_{4}{ }^{+}$cations with increasing crystallization times. In both situations the water desorption intensity decreases significantly with the crystallization time until nHAST-144h composite sample (prepared with $144 \mathrm{~h}$ of crystallization), suggesting no more exchange of $\mathrm{Ca}^{2+}$ by $\mathrm{NH}_{4}{ }^{+}$ions would occur beyond this time. In line with this, the amount of loosely-bound water (weight loss below $130{ }^{\circ} \mathrm{C}$ ) increases accordingly with the crystallization time. In addition, nHAST composite samples showed an additional broad weight loss at around $450{ }^{\circ} \mathrm{C}$ due to deammoniation, indicating the release of $\mathrm{NH}_{3}$ as $\mathrm{NH}_{4}$-STI (after exchange of $\mathrm{Ca}^{2+}$ by $\mathrm{NH}_{4}{ }^{+}$) transforms into H-STI [30]. The deammoniation band shows a higher intensity with increasing the crystallization time, indicating the release of a higher amount of $\mathrm{NH}_{3}$ and thus, again indicating the progress of the ion-exchange, $\mathrm{Ca}^{2+}$ by $\mathrm{NH}_{4}{ }^{+}$ions, with the crystallization time. Therefore, we can conclude that the amount of $\mathrm{Ca}^{2+}$ ions released to the solution has increased as a function of the crystallization time, leading to the crystallization of a proportionate increasing amount of HAp on the STI surface. Nevertheless, the deammoniation peak of nHAST-144h sample occurred at a slightly higher temperature of about $465{ }^{\circ} \mathrm{C}$, possibly due to the phase transition of the STI zeolite from monoclinic to orthorhombic, due to the total exchange of $\mathrm{Ca}^{2+}$ in STI by $\mathrm{NH}_{4}{ }^{+}$ions in nHAST-144h sample. 
ATR -Infrared studies (Figure 5) show IR features at about 565, 606 and $1020 \mathrm{~cm}^{-1}$, which are consistent with the presence of $\mathrm{PO}_{4}{ }^{3-}$ groups (marked with blue arrows) [32], whose intensity increases with the crystallization time, suggesting again the formation of a higher amount of HAp on the STI surface with longer times. Additionally, a new band arises at about $1430 \mathrm{~cm}^{-1}$ (marked with black arrow) due to the presence of $\mathrm{NH}_{4}{ }^{+}$ions during the HAp crystallization (after exchange with $\mathrm{Ca}^{2+}$ ). This contributes to confirm what was suggested by XRD and TGA that the chemical treatment with ammonium phosphate caused a progressive (with time) cation exchange of $\mathrm{Ca}^{2+}$ by $\mathrm{NH}_{4}^{+}$.

Studies on the point of zero charge (Figure SI-1) were conducted using potentiometric mass titration to determine the modification of the surface charge properties of the parent STI zeolite upon modification with HAp. The PZC of the nHAST-144h composite was determined to be 10, significantly high as compared to the very low PZC of the parent STI zeolite support of only 2.1, indicating that below $\mathrm{pH} 10$ the surface of nHAST-144h is positively charged. This finding indicates an inversion of the adsorption properties of the zeolite, which is now turned into a positively charged surface at almost all range of $\mathrm{pH}$, thus promoting a successful adsorption of an anion like $\mathrm{F}^{-}$via electrostatic interactions on the external surface.

ICP analysis (Table 1) showes a constant amount of $\mathrm{Ca}^{2+}$ in the final composites, whilst the amount of P gradually increased; this confirms that the amount of HAp grown on the zeolite surface is also increasing with the crystallization time, as can be clearly observed in Figure 6-left (black line). Interestingly, the defluoridation capacity of the resulting composites (red line in Figure 6-left) increases also with the crystallization time and thus with the content of HAp in the composite (although the increasing trends (slopes) are not exactly equivalent at long crystallization times), reaching a significantly high fluoride-removal efficiency (about $86 \%$ in 
the nHAST composite crystallized for $144 \mathrm{~h}$, from water with $10 \mathrm{mg} / \mathrm{L}$ of fluoride concentration and $10 \mathrm{~g} / \mathrm{L}$ dosage). The corresponding final equilibrium $\mathrm{F}^{-}$concentration was $1.60 \mathrm{mg} / \mathrm{L}$, almost the same as the maximum permissible WHO limit, $1.5 \mathrm{mg} / \mathrm{L}$ (higher doses clearly overpass this threshold), giving a total defluoridation capacity of $0.86 \mathrm{mg} / \mathrm{g}$ for composite nHAST-144h. Interestingly, at the same adsorbent dose, if the initial fluoride concentration lowers to $5 \mathrm{mg} / \mathrm{L}$ (Figure SI-2), the fluoride-removal efficiency is higher, about $95 \%$, yielding in this case the final equilibrium $\mathrm{F}^{-}$concentration of $0.25 \mathrm{mg} / \mathrm{L}$, significantly lower than the WHO safe range.

If we normalize the fluoride-removal capacity to the amount of HAp present in the adsorbent (determined from ICP P content, Table 1), to give the corresponding HAP intrinsic capacity, calculated as $\mathrm{mg}$ of $\mathrm{F}^{-}$per gram of HAp following eq. 4 (Figure 6-left, blue line), we observe an extremely high intrinsic capacity for the HAp in the nHAST composite obtained at low crystallization times (nHAST-2h, with a HAp capacity of $17.28 \mathrm{mg} / \mathrm{g}$ of HAp). Given that the theoretical maximum value for a full exchange of $\mathrm{F} / \mathrm{OH}$ would be $37.8 \mathrm{mg} / \mathrm{g}$ of HAp, this value is extremely high. Indeed it is significantly higher than that of other adsorbents based on Hydroxyapatite such as organic bone char [33], evidencing that the HAp nanocrystals are extremely small in this composite; however, the total capacity of this composite is not very high $(0.32 \mathrm{mg} / \mathrm{g})$ because of the low amount of HAp grown. When the crystallization time increases, and hence the amount of HAp grown on the zeolite surface, the intrinsic capacity of the resulting HAp nanocrystals gradually decreases from $\sim 17$ down to a plateau value of $\sim 10 \mathrm{mg} / \mathrm{g}$ of HAp (Figure 6-left, blue line), indicating that these nanocrystals are slightly less effective for defluoridation (though still much more active than usual HAp materials). Indeed, a direct relationship between the amount of HAp grown on the surface and the intrinsic capacity of the resulting HAp is clearly appreciated (Figure 6-right). This indicates that longer crystallization 
times involves a higher amount of HAp nanocrystals but slightly less efficient because of the enlargement of the nHAp crystals. Hence, these observations indicate two opposite trends, low crystallization times involve the growth of a low amount of extremely small and extraordinarily efficient HAp nanocrystals, yet resulting in a low total defluoridation capacity because of the small amount of HAp. Longer crystallization times result in the growth of more and larger nanocrystals, being slightly less efficient for defluoridation, but this is widely compensated by the higher amount of HAp, resulting in very efficient nHAST composites for defluoridation, with capacities reaching up to $0.86 \mathrm{mg} / \mathrm{g}$.

In order to fully understand the nature of the nHAp crystals grown on the surface of the zeolite and how it affects the fluoride removal performance, further studies of selected samples, nHAST-19h and $-144 \mathrm{~h}$, were carried out using ${ }^{31} \mathrm{P}$ MAS-NMR and Advanced Electron Microscopy Techniques. ${ }^{31}$ P MAS-NMR spectra of the composites nHAST-19h (green line) and nHAST-144h (blue line) synthesized at $\mathrm{pH} 8$ are plotted in Figure 7. Two other NMR spectra, nHAST-19h at crystallization $\mathrm{pH}$ of 9 (red line) taken from our previous work [25], and a typical HAp (dotted black line) sample, were included for comparison purposes. In all the samples the same $\mathrm{P}$ resonance is observed at around $2.85 \mathrm{ppm}$, characteristic of $\mathrm{P}$ in HAp, confirming the formation of HAp in the composites [34, 35]. However, in nHAST-19h (green line) and nHAST144h (blue line) composites synthesized at crystallization $\mathrm{pH}$ of 8 in the present study, the band is broader as compared to the typical HAp materials (dotted black line); furthermore, a shoulder at around $0 \mathrm{ppm}$ is observed, both being features related to the nanometric nature of HAp crystals [25,36]. Interestingly, the NMR spectra of the two composites, nHAST-19h and nHAST144h, synthesized at crystallization $\mathrm{pH} 8$ were even broader than the nHAST-19h composite 
synthesized at crystallization $\mathrm{pH} 9$ (red line), suggesting the presence of smaller HAp particles in nHAST composites prepared at $\mathrm{pH} 8$.

Spherical aberration (Cs) corrected scanning transmission electron microscopy (STEM) coupled with High Angular Annular Dark Field (HAADF) detector was chosen to study nHAST-19h and nHAST-144h composite samples in order to fully comprehend the evolution of the HAp crystallized on the STI surface as a function of the crystallization time. Cs-STEM high-resolution imaging allowed observing the growth of small particles of nHAp (Figure 8a) that grew forming very thin fibers decorating the surface of the STI crystals in nHAST-19h. These high resolution observations allowed investigating the HAp crystals over the STI surface. HAp nanocrystals are clearly appreciated in the images as very thin hairy crystals protruding from the STI homogeneous surface. The layered structure of these fibers can be identified with a d-spacing of $2 \AA$ (Figure 8b) which is the highest resolution ever reported for HAp structure. As crystallization time increases to 144 hours, the growth of HAp fully covers the surface of the STI crystals in a heterogeneous manner but yet, linked to the zeolite crystals, i.e. no separate HAp crystals are observed, which means that the surface of the stilbite acts as source of nucleation points; the crystals grow to connect these nuclei leading to a fully-covered surface, as shown in Figure 8c. In other words, longer times lead to a higher release of $\mathrm{Ca}^{2+}$ from the zeolite, as previously shown, and these cations promote the growth of a very thin layer of nHAp wrapping up the STI crystals as shown in Figure 8c. Indeed, significantly higher amounts of HAp crystals are clearly observed in nHAST-144h sample (Figure 8c) as hairy needles, while at shorter crystallization time, nHAST-19h, the images reveal abundant number of particles in which the smooth surface of the zeolite crystals could still be observed (Figure 8a). The chemical composition of these nanocrystals could be extracted using Electron Energy Loss Spectroscopy 
(EELS). STEM/HAADF/EELS mapping (Figure 8d) analysis performed over the area marked with a white rectangle (Figure 8d) clearly shows the crystallization of HAp on the external surface of the STI zeolite, distinguishable by its main constituent element P (Figure 8e), in blue colour (not present in the STI zeolite), attached to the surface of the zeolite crystals, whose identifying element is $\mathrm{Si}$ (red colour). As can be observed in nHAST composite samples, red color follows a sharp surface corresponding to the STI crystal, whereas green $(\mathrm{Ca})$ and blue $(\mathrm{P})$ colors of HAp draws thin irregular forms on the surface of STI zeolite.

In summary, the nanometric nature of the crystallized HAp relies on the slow release of $\mathrm{Ca}^{2+}$ from the zeolite leading to a much higher $\mathrm{F}^{-}$-removal efficiency of HAp on the composite. However, larger extent of Ca exchange and consequently larger amounts of HAp also involves slightly lower intrinsic defluoridation capacities of the HAp crystals as they grow. Therefore, a crystallization time of $144 \mathrm{~h}$ is considered as an optimum compromise time between both opposite trends to perform further adsorption studies.

\subsection{Effect of the defluoridation parameters on the adsorption capacity of nHAST}

The influence of the adsorbent dose on the fluoride-removal efficiency of nHAST-144h adsorbent was studied at 4, 6, 8, 10 and $12 \mathrm{~g} / \mathrm{L}$ doses. Batch adsorption studies were performed using initial fluoride concentrations of 5 and $10 \mathrm{mg} / \mathrm{L}$, a contact reaction time of 20 hours and at room temperature. As described in Figure 9, the fluoride-removal efficiency notably increases with increasing the adsorbent dose up to $10 \mathrm{~g} / \mathrm{L}$ due to the availability of a higher number of fluoride binding sites. Fluoride removals of about 95 and $84 \%$ were found at doses of $10 \mathrm{~g} / \mathrm{L}$ from 5 and $10 \mathrm{mg} / \mathrm{L}$ initial fluoride concentrations, respectively. Because the equilibrium 
fluoride concentration falls within the WHO limit, a dose of $10 \mathrm{~g} / \mathrm{L}$ was considered as an optimum dose for further adsorption experiments.

In order to identify the dynamics of the adsorption process, batch experiments were carried out using different contact times, with the optimized dose of $10 \mathrm{~g} / \mathrm{L}$ and $10 \mathrm{mg} / \mathrm{L}$ of initial fluoride concentration at room temperature. As shown in Figure 10A, a rapid fluoride removal was observed up to 8 hours, reaching about $81 \%$ of $\mathrm{F}^{-}$-removal. The reaction proceeds slowly until 20 hours where the equilibrium is reached, giving a fluoride-removal efficiency of about $84 \%$. Since there is no significant increase of the fluoride adsorption beyond, a contact time of 20 hours was fixed for further studies. Composite nHAST-144h adsorbent shows significantly high performance due not only to the presence of new active sites, but the high efficiency of nanometric size HAp crystals, as evidenced by ${ }^{31} \mathrm{P}$ MAS-NMR and Cs-STEM analyses. Most probably, in the first 8 hours the driving force for defluoridation is the anion exchange of fluoride in solution with surface hydroxyl ions of the nano-HAp. Later on, the slow adsorption is probably the result of the diffusion of the adsorbed external fluoride to the inner adsorbent surface, providing then new F-binding sites on the external surface.

The effect of initial fluoride concentration was studied using fluoride concentrations ranging from 2 to $200 \mathrm{mg} / \mathrm{L}$ (Figure 10B). The defluoridation capacity increases with increasing the initial fluoride concentration, up to a value of $\sim 4 \mathrm{mg} / \mathrm{g}$ from an initial fluoride concentration of 200 $\mathrm{mg} / \mathrm{L}$.

The effect of the water $\mathrm{pH}$ was investigated with an initial fluoride concentration of $10 \mathrm{mg} / \mathrm{L}$, adsorbent dose of $10 \mathrm{~g} / \mathrm{L}$, contact time of 20 hours and at room temperature conditions; water $\mathrm{pH}$ was varied from 3 to 10 , using $0.1 \mathrm{M} \mathrm{HCl}$ or $0.1 \mathrm{M} \mathrm{NaOH}$. Figure $10 \mathrm{C}$ shows that, in contrast to other adsorbents, no strong effect is observed on the $\mathrm{F}^{-}$-removal ability as a function of the water 
$\mathrm{pH}$. A very soft decrease in the $\mathrm{F}^{-}$-removal is observed when increasing the water $\mathrm{pH}$ from 3 to 8 , and then a slightly stronger reduction occurs at very basic pHs of 9 and 10, but still reaching about $79 \%$ fluoride-removal at $\mathrm{pH} 10$, being only $7 \%$ lower than the maximum efficiency at $\mathrm{pH}$ 3. Hence, our composite is quite robust against modifications in the water pHs. The small effect of the water $\mathrm{pH}$ in fluoride removal of nHAST adsorbent may be attributed to the nature of its surface charge, as evidenced by its high PZC. Anyhow, the slightly higher efficiency at pH less than 6.5 may be due to the gradual increase in attractive forces, whereas the relatively lower efficiency in alkaline medium can be explained by the competition between the $\mathrm{OH}^{-}$and $\mathrm{F}^{-}$ions for the adsorption sites. It is known that most adsorbents used in fluoride-removal have narrow working $\mathrm{pH}$ ranges, and usually show optimum performance in acidic $\mathrm{pH}$ range. However, the $\mathrm{pH}$ of natural groundwater with high fluoride content is in the range of 7.6 to 8.6 in most cases $[37,38]$. Within this $\mathrm{pH}$ range, unlike most other defluoridation adsorbents, nHAST-144h composite shows high performance, about $84 \%$ of F-removal efficiency. Interestingly, the performance remains comparably high in the $\mathrm{pH}$ range under investigation: the F-removal varies between $79 \%$ at pH 10 to $86 \%$ at $\mathrm{pH} 3$ (at a dose of $10 \mathrm{~g} / \mathrm{L}$ and initial fluoride concentration of $10 \mathrm{mg} / \mathrm{L})$.

A wide variety of other anions is generally present in groundwater, and may compete with fluoride ions for adsorption on nHAST composite. In order to investigate their effect on the fluoride removal, batch adsorption experiments were performed in the presence of 100-500 $\mathrm{mg} / \mathrm{L}$ concentrations of chloride, sulfate and bicarbonate in solutions with $10 \mathrm{mg} / \mathrm{L}$ of fluoride concentration; Figure 10D describes their effect on the fluoride-removal efficiency of nHAST144h. When no competing ions were present, about $84 \%$ of fluoride was adsorbed; the final residual solution $\mathrm{pH}$ in this case was about 7 . In the presence of bicarbonate ions, the fluoride- 
removal efficiency decreases while increasing the concentration. This effect is significant at concentrations higher than $300 \mathrm{mg} / \mathrm{L}$ : the efficiency decreased significantly from about $84 \%$ to $65 \%$ in the presence of $500 \mathrm{mg} / \mathrm{L} \mathrm{HCO}_{3}{ }^{-}$ions, possibly due to the change in $\mathrm{pH}$ as well as the strong competing effect of $\mathrm{HCO}_{3}{ }^{-}$ions. However, other ions such as chloride and sulfate showed no significant effect within the concentration range tested. In general, the change in removal efficiency when the coexisting ion concentration is below $300 \mathrm{mg} / \mathrm{L}$ is almost insignificant, again evidencing a high robustness of our adsorbent against changes in the chemical composition of the water.

\subsection{Defluoridation of real groundwater from Ethiopian Rift Valley using nHAST-144h}

Finally, the defluoridation potential of nHAST-144h with fluoride-containing real groundwater samples (samples 1 and 2 in Figure 10B), collected from a village near Maki town, in the Ethiopian Rift Valley, was tested; Table 2 lists the chemical composition of the water before and after the treatment. When untreated water of samples 1 and 2 were subjected to a defluoridation treatment at a dose of $10 \mathrm{~g} / \mathrm{L}$ of nHAST $-144 \mathrm{~h}$ and a contact time of 20 hours, about $83 \%$ of fluoride was removed in both cases; the corresponding final fluoride concentrations were found to be 1.2 and $1.4 \mathrm{mg} / \mathrm{L}$, respectively (below the WHO threshold), giving the same final $\mathrm{pH}$ of about 8.1. The defluoridation capacities obtained for groundwater samples 1 and 2 were found to be 0.6 and $0.68 \mathrm{mg} \mathrm{F} / \mathrm{g}$, respectively, which falls well within the trend of nHAST-144h as a function of the fluoride initial concentration (Figure 10B); their defluoridation capacities were found to be only slightly lower than that in lab-made fluoridated water solution, possibly due to the presence of various competing ions in real groundwater. In fact, chloride and sulfate concentrations are also reduced during the defluoridation treatment (Table 2), whilst $\mathrm{pH}$ remains 
practically the same. In sum, these results with real groundwater support the potential use of nHAST-144h as adsorbent for defluoridation in a real case.

\subsection{Reproducibility using other Stilbite samples}

Reproducibility of the optimized synthesis procedure for the preparation of nHAST adsorbents was successfully tested using other similar natural stilbite zeolites (labeled Z4-Z9) collected from different parts of the country by the School of Earth Sciences (Addis Ababa University). The main stilbite sample used in this work was collected from the Hashenge basalt formation in the Tigrai region, and the rest of the samples were collected in the localities of Korem and Maychew in the same region. All zeolite samples (Z4-Z9) involved in the preparation of nHA/zeolite composites were first studied by XRD and ICP in order to identify the zeolitic structure and composition. All the samples were identified as stilbite minerals, and the ICP analyses confirmed a high Ca content (Table 3). For Z4-Z9 zeolite samples, the corresponding nHA/Z4-Z9 composites were synthesized following the optimized synthesis procedure (autogeneous $\mathrm{pH}$ of 8 , crystallization time of $144 \mathrm{~h}$ at room temperature). The composites were characterized and then tested in fluoride-removal, and their performances were compared with the nHAST-144h composite reported above. The X-Ray diffraction patterns of the synthesized nHA/Z4-Z9 composite samples show very similar diffraction patterns (Figure SI-3), suggesting that the crystalline structure of all the zeolites did not change after the growth of HAp on the zeolite surface. Similarly, the presence of HAp was confirmed by the P content in the final composites, as determined by ICP elemental analysis (Table 3). Again, the amount of HAp (calculated by the P content using eq. 1) grown on the zeolite surfaces was in the range between $5.4 \%$ in nHAZ9 to $10.8 \%$ in nHAZ4 and nHAZ5. This confirms the reproducibility of the synthesis procedure. 
However, the amount of HAp crystallized is not exactly the same, which might be associated to a different roughness of the zeolite surface involving a different amount of nucleation points for the HAp growth.

Defluoridation tests were performed using $10 \mathrm{mg} / \mathrm{L}$ of initial fluoride concentration at $10 \mathrm{~g} / \mathrm{L}$ dose. The fluoride-removal efficiencies of all the nHA/zeolite composites were significantly high, indicating the formation of a high amount of active nHA sites on the zeolite surface. Maximum fluoride-removal of $93 \%$ was recorded for nHAZ4, whereas the minimum $75 \%$ removal was observed for nHAZ7 composite (Table 3). Interestingly, all the composites were able to reduce the fluoride concentration below or at least close to the WHO maximum limit of $1.5 \mathrm{mg} / \mathrm{L}$ from an initial fluoride concentration of $10 \mathrm{mg} / \mathrm{L}$. Thus, this study corroborates the reproducibility of the no-energy demanding synthetic procedure proposed, which can be reproduced with different stilbite zeolite samples from different potential mineral deposits.

\section{Conclusions}

In this study, the optimization of the synthesis parameters allowed a strict control of the crystal growth of nanometric Hydroxyapatite on the surface of the natural stilbite zeolite. Interestingly, an autogenous $\mathrm{pH}$ of 8 , and a crystallization time of 144 hours at room temperature enabled the crystallization of nano-sized hydroxyapatite crystals in a very sustainable manner. Cs-STEM and

${ }^{31} \mathrm{P}$ NMR analyses provide evidences for the formation of nano-crystals of HAp, which explains their high $\mathrm{F}^{-}$-removal activity. Defluoridation tests confirm the high potential of nHAST composites for fluoride-removal under very demanding conditions, in solutions with 5.0 and 10 $\mathrm{mg} / \mathrm{L}$ of fluoride initial concentration, overpassing the WHO limit with a dose of $10 \mathrm{~g} / \mathrm{L}$. Even with real groundwater, the optimized nHAST-144h composite has shown a high fluoride-uptake 
capacity. Fluoride adsorption was very modestly influenced by the presence of co-ions and shows a minimal effect of the water $\mathrm{pH}$, both of which add value to the use of nHAST composites for $\mathrm{F}^{-}$-removal from groundwater. The intrinsic HAp capacity of nHAST, normalized to the amount of HAp on the adsorbent, is significantly high ( $9.15 \mathrm{mg} / \mathrm{gHAp})$, showing the high $\mathrm{F}^{-}$-removal efficiency of HAp on these composites. These results foresee a potential of nHAST144h composite towards fluoride-removal implementation, particularly under the constraint of low energy demanding environments like Ethiopia.

\section{Acknowledgments}

The authors acknowledge Dr. Asfawossen Asrat, Prof. Solomon Tadesse, and Dr. Dereje Ayalew, School of Earth Sciences, Addis Ababa for providing the natural zeolites from Ethiopia. Spanish Government, MINECO MAT2012-31127 project and the Spanish Research Council CSIC I-COOP-H $\mathrm{H}_{2} \mathrm{O}$ (2013CD0009), are acknowledge for funding. LGH acknowledges the Spanish Ministry of Economy and Competitivity for Ramón y Cajal (RYC-2012-11794) contract.

\section{References}

[1] N. J. Chinoy, M. V. Rao, M. V. Narayana, E. Neelakanta, Reprod. Toxicol. 5 (1991) 505512.

[2] I. Abe, S. Iwasaki, T. Tokimoto, N. Kawasaki, T. Nakamura, S. Tanada, J., Colloid. Interface Sci. 275 (2004) 35-39.

[3] M. Hichour, F.Persin, J.Sandeaux, C. Gavach, Sep. Purif. Technol. 18 (2000) 1-11. 
[4] WHO,Guidelines for Drinking Water Quality, Health Criteria and Other Information, second ed., Vol. 2,World Health Organization, Geneva, Switzerland, (1996).

[5] WHO,Guidelines for Drinking Water Quality, Recommendations, Vol. 1, World Health Organization, Geneva, Switzerland, (1984).

[6] UNICEF's Position on Water Fluoridation: http://www.nofluoride.com/Unicef fluor.cfm; consulted on march 31, (2014).

[7] H. Kloos, R.TekleHaimanot.Trop. Med. Int. Health, 4 (1999) 355-364.

[8] R. Tekle-Haimanot, A. Fekadu, B. Bushera, Y. Mekonnen, First International Workshop on Fluorosis Prevention and Defluoridation of Water, Int. Soc. Fluoride Res. Eds., Ngurdoto, Tanzania, Oct. (1995) 18-22.

[9] F. Díaz-Barriga, A. Navarro-Quezada, M. I. Grijalva , M. Grimaldo , J. P. Loyola-Rodríguez, M. Deogracias-Ortiz, Fluoride 30 (1997) 233-239.

[10] L. Galicia Chacón, N. Molina Frechero, A. Oropeza, E. Gaona, L. Juárez López, Rev. Int. Contam. Ambie. 27 (2011) 283-289.

[11] J. Mullen, Br. Dent. J. 199 (2005) 1-4.

[12] S. Jagtap, M. K. Yenkie, N. Labhsetwar, S. Rayalu, Chem. Rev., (2012) 2454-2466.

[13] L.E.L. Hammari, A. Laghzizil, P. Barboux, K. Lahlil, A. Saoiabi, J. Hazard. Mater., B114 (2004) 41-44

[14] V.E. Badillo-Almaraz, J.A. Flores, H. Arriola, F.A. López, L. Ruiz-Ramírez, J. Radioanal. Nucl. Chem., 271 (2007) 741-744.

[15] M. Jiménez-Reyes, M. Solache-Ríos, J. Hazard. Maters., 180 (2010) 297-302

[16] M. Mourabet, A. El Rhilassi, H. El Boujaady, M. Bennani-Ziatni, R. El Hamri, A. Taitai, J. Saudi Chem.Soc., 19 (2015), 603-615. 
[17] S.C. Sundaram, N. Viswanathan, S. Meenakshi, J. Hazard. Mater., 155 (2008) 206-215.

[18] S. Gao, R. Sun, Z.G. Wei, H.Y. Zhao, H.X. Li, F. Hu, J. Fluorine Chem., 130 (2009) 550556.

[19] G. E. J. Poinern, M. K. Ghosh, Ng. Yan-Jing, T. B. Issa, S. Anand, P. Singh, J. Hazard. Mater., 185 (2011) 29-37.

[20] V. Sternitzke, R. Kaegi, A. Jean-Nicolas, E. Lewin, J. G. Hering, and C. A. Johnson, Sci. Technol., 46 (2012) 802-809.

[21] D. Zhang, H. Luo, L. Zheng, K. Wang, H. Li, Y. Wang, H. Feng, J.Hazard. Mater., 241-242 (2012) 418-426.

[22] C. S. Sundaram, N. Viswanathan, S. Meenakshi, J. Hazard.Mater., 172 (2009) 147-151.

[23] L. Feng, W. Xu, T. Liu, J. Liu, J. Hazard. Mater., 221-222 (2012) 228-235.

[24] K. Pandi, N. Viswanathan, Carbohydr. Polym., 112 (2014) 662-667.

[25] L. Gómez-Hortigüela, J. Pérez-Pariente, Y. Chebude, I. Díaz, RSC Adv., 4 (2014) 79988003.

[26] S. Alemu, E. Mulugetaa, F. Zewgea, B.S. Chandravanshi, Environ. Technol., 35 (2014) 1893-1903.

[27] K. Bourikas, J. Vakros, Ch. Kordulis, A. Lycourghiotis, J. Phys. Chem., 107 (2003) 94419451.

[28] T.A. Aoba, Crit.Rev. Oral Bio.Med., 8 (1997) 136-153.

[29] A. Tamiru, Eth. J. Sci., 16 (1993) 43-59.

[30] L. Gómez-Hortigüela, A.B. Pinar, J. Pérez-Pariente, T. Sani, Y. Chebude, I. Díaz, Micropor. Mesopor. Mater., 193 (2014) 93-102. 
[31] M.M.J. Treacy, J.B.Higgins, Collection of simulated XRD power patterns for zeolites, Elsevier, (2001).

[32] Y. Watanabe, Y. Moriyoshi, Y. Suetsugu, T. Ikoma, T. Kasama, T. Hashimoto, H. Yamada, J. Tanaka, J. Am. Ceram. Soc., 87 (2004) 1395-1397.

[33] T. Sani, L. Gómez-Hortigüela, J. Pérez-Pariente, Y. Chebude, I. Díaz Sep. Purif. Technol. 157 (2016) 241-248.

[34] R.N. Panda, M.F. Hsieh, R.J. Chung, T.S. Chin, J.Phys. Chem. Solids, 64 (2003) 193-199.

[35] C. Drouet, BioMed Res. Int., (2013), Article ID 490946.

[36] C. Jäger, T. Welzel, W. Meyer-Zaika, M. Epple, Magn. Reson. Chem., 44 (2006) 573-580.

[37] S. Ayoob, A.K. Gupta, Environ. Sci.Technol., 36 (2006) 433-487.

[38] C.M. Kanno, R. L. Sanders, S. M. Flynn, G. Lessard, S. C. B. Myneni, Environ. Sci. Technol., 48 (2014) 5798-5807. 
Table 1: ICP elemental analysis results of the original STI zeolite and of nHAST composites synthesized as a function of crystallization $\mathrm{pH}$ and time.

\begin{tabular}{|c|c|c|c|c|c|c|c|}
\hline Sample & $\operatorname{Al}(\%$ wt $)$ & Si (\% wt) & Si/Al & $\mathrm{Ca}(\% \mathrm{wt})$ & $\mathrm{Na}(\%$ & wt)P $(\%$ wt $)$ & НАр \% \\
\hline$\overline{\mathrm{STI}}$ & 8.0 & 20.4 & 2.4 & 4.9 & 0.50 & 0.0 & - \\
\hline nHAST 7.0 & 7.7 & 22.2 & 2.7 & 4.7 & 0.3 & 0.9 & 4.9 \\
\hline nHAST 7.5 & 7.7 & 22.6 & 2.7 & 4.8 & 0.3 & 0.8 & 4.3 \\
\hline nHAST 8.0 & 7.3 & 20.9 & 2.7 & 4.7 & 0.2 & 0.9 & 4.9 \\
\hline nHAST 8.5 & 7.5 & 20.4 & 2.5 & 4.7 & 0.2 & 0.8 & 4.3 \\
\hline nHAST 9.0 & 7.5 & 20.2 & 2.5 & 4.7 & 0.2 & 0.9 & 4.9 \\
\hline nHAST 9.5 & 7.7 & 20.5 & 2.5 & 4.7 & 0.3 & 0.9 & 4.9 \\
\hline nHAST 10.0 & 7.7 & 20.2 & 2.4 & 4.8 & 0.3 & 0.9 & 4.9 \\
\hline nHAST, $2 \mathrm{~h}$ & 8.2 & 19.4 & 2.2 & 5.4 & 0.4 & 0.3 & 1.6 \\
\hline nHAST, 6h & 8.5 & 20.6 & 2.3 & 5.5 & 0.4 & 0.6 & 3.2 \\
\hline nHAST, 19h & 8.2 & 19.3 & 2.2 & 5.6 & 0.4 & 0.9 & 4.9 \\
\hline nHAST, $72 \mathrm{~h}$ & 8.2 & 20.4 & 2.3 & 5.6 & 0.2 & 1.4 & 7.6 \\
\hline nHAST, 96h & 8.4 & 20.1 & 2.2 & 5.6 & 0.2 & 1.6 & 8.6 \\
\hline nHAST, $144 \mathrm{~h}$ & 8.5 & 20.5 & 2.2 & 5.5 & 0.2 & 1.7 & 9.2 \\
\hline
\end{tabular}


Table 2: Physicochemical parameters of groundwater samples before and after treatment with nHAST-144h adsorbent at a dose of $10 \mathrm{~g} / \mathrm{L}$ and a contact time of 20 hours.

\begin{tabular}{lcccc}
\hline \multirow{2}{*}{ Parameter } & \multicolumn{2}{c}{ Water Sample-1 } & \multicolumn{2}{c}{ Water Sample-2 } \\
& Untreated & Treated & Untreated & Treated \\
\hline Fluoride, $\mathrm{mg} / \mathrm{L}$ & 7.2 & 1.2 & 8.2 & 1.4 \\
Chloride, $\mathrm{mg} / \mathrm{L}$ & 24.1 & 8.1 & 19.5 & 7.9 \\
Sulphate, $\mathrm{mg} / \mathrm{L}$ & 72.0 & 48.0 & 76.0 & 49.0 \\
$\mathrm{pH}$ & 8.3 & 8.1 & 8.3 & 8.1 \\
\hline
\end{tabular}


Table 3: ICP elemental analysis results of nHAZ4-nHAZ9 composite samples synthesized at the optimized procedure, and fluoride removal (F-Rem\%) from water with $10 \mathrm{mg} / \mathrm{L}$ of $\mathrm{F}$ initial concentration (dose of $10 \mathrm{~g} / \mathrm{L}$ and contact time of $20 \mathrm{~h}$ ).

\begin{tabular}{lccccccc}
\hline Sample & Al wt $\%$ & Si wt $\%$ & Na wt $\%$ & Ca wt $\%$ & P wt \% & HAp \% & F-Rem \% \\
\hline nHAST144h & 8.5 & 20.5 & 0.2 & 5.5 & 1.7 & 9.2 & 84.0 \\
nHAZ4 & 7.2 & 20.2 & 0.1 & 5.1 & 2.0 & 10.8 & 93.3 \\
nHAZ5 & 7.3 & 20.6 & 0.1 & 5.1 & 2.0 & 10.8 & 82.8 \\
nHAZ6 & 7.6 & 21.8 & 0.1 & 5.2 & 1.2 & 6.5 & 82.3 \\
nHAZ7 & 7.2 & 20.7 & 0.1 & 4.9 & 1.9 & 10.3 & 74.7 \\
nHAZ8 & 7.3 & 21.4 & 0.1 & 5.2 & 1.1 & 5.8 & 78.8 \\
nHAZ9 & 7.1 & 21.0 & 0.1 & 5.1 & 1.0 & 5.4 & 76.5 \\
\hline
\end{tabular}


Figure 1: XRD profiles of the original STI zeolite and nHAST composite samples as a function of the crystallization $\mathrm{pH}$.

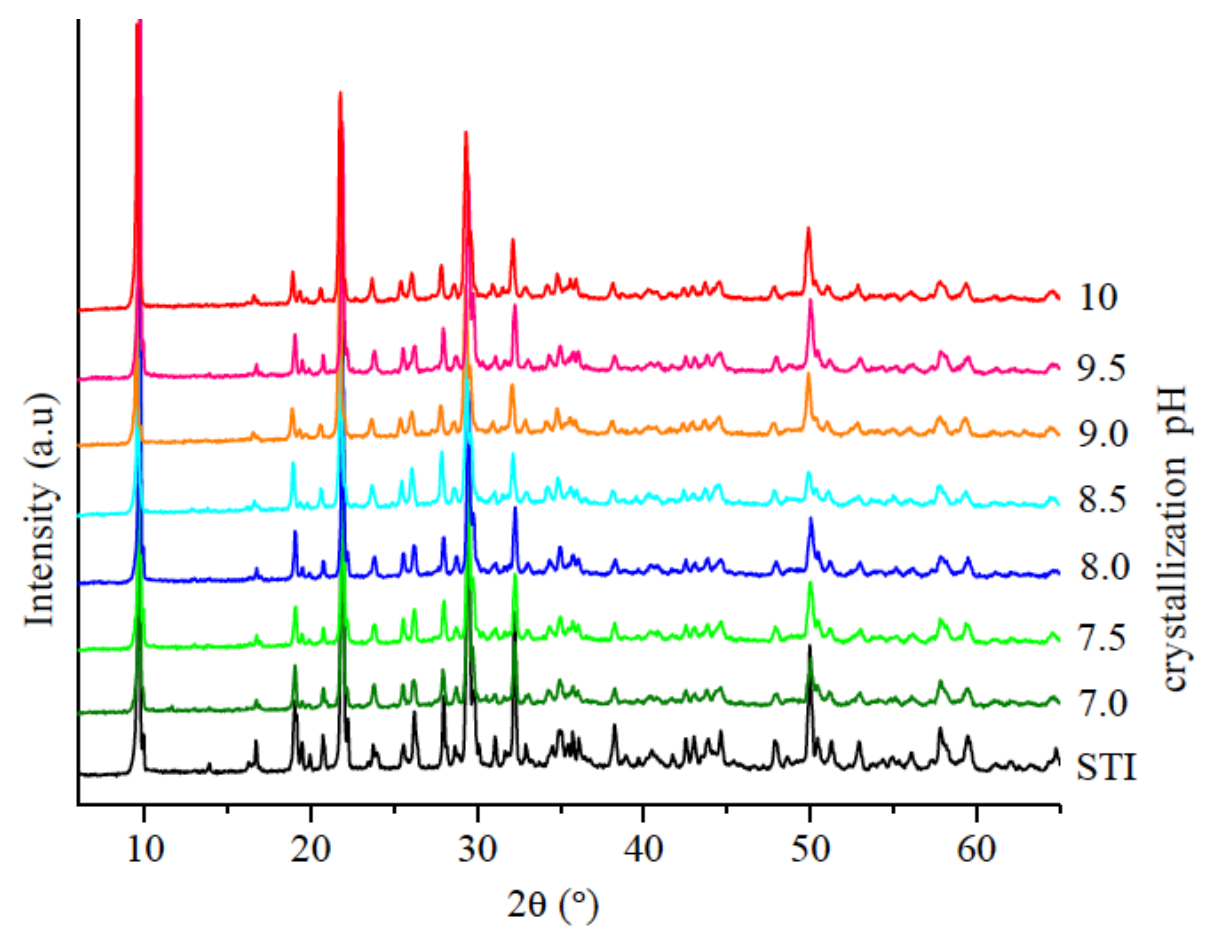


Figure 2: Defluoridation performance of nHAST composites as a function of crystallization $\mathrm{pH}$, from water with a) $5 \mathrm{mg} / \mathrm{L}$ (green line) and b) $10 \mathrm{mg} / \mathrm{L}$ (blue line) initial fluoride concentrations; cross signs are for $\mathrm{F}^{-}$removal efficiency (right axis), and triangles for defluoridation capacity (left axis).

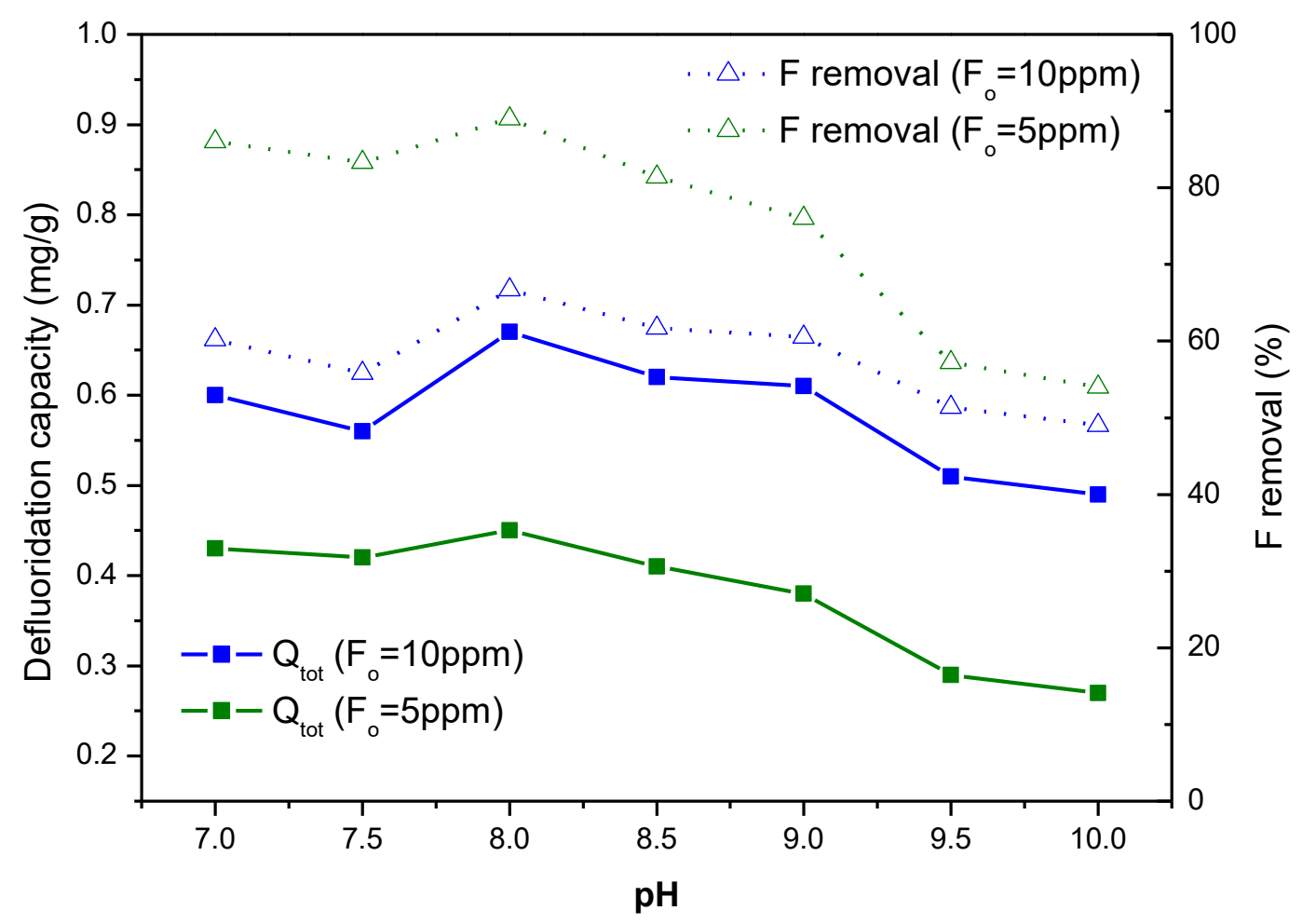


Figure 3: XRD profiles of the original STI zeolite and nHAST composite samples as a function of the crystallization time. Right: detail of the 23-25 $2 \theta$ region.

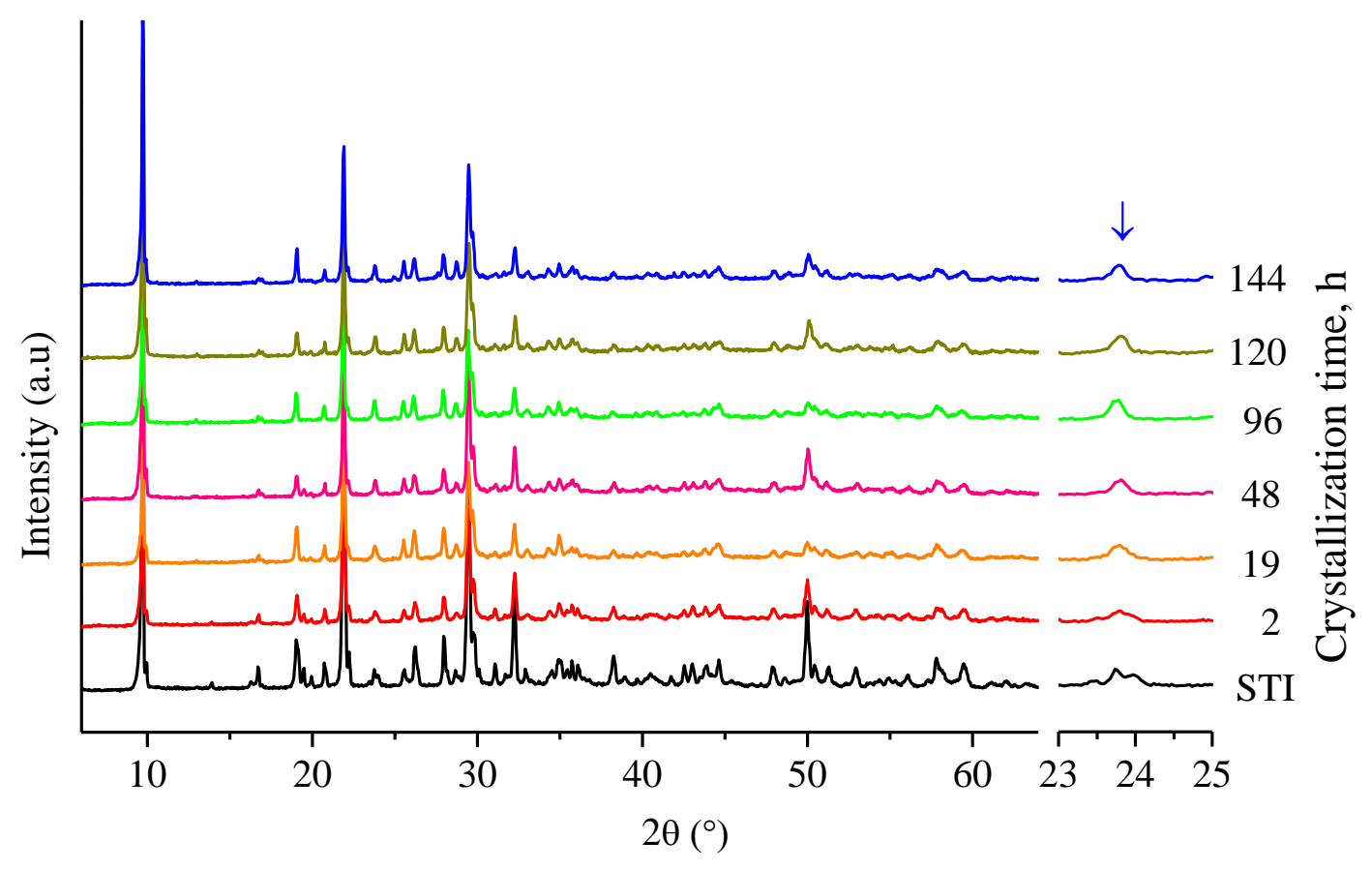


Figure 4: TGA (doted lines) and DTG (solid lines) of STI and nHAST composite samples.

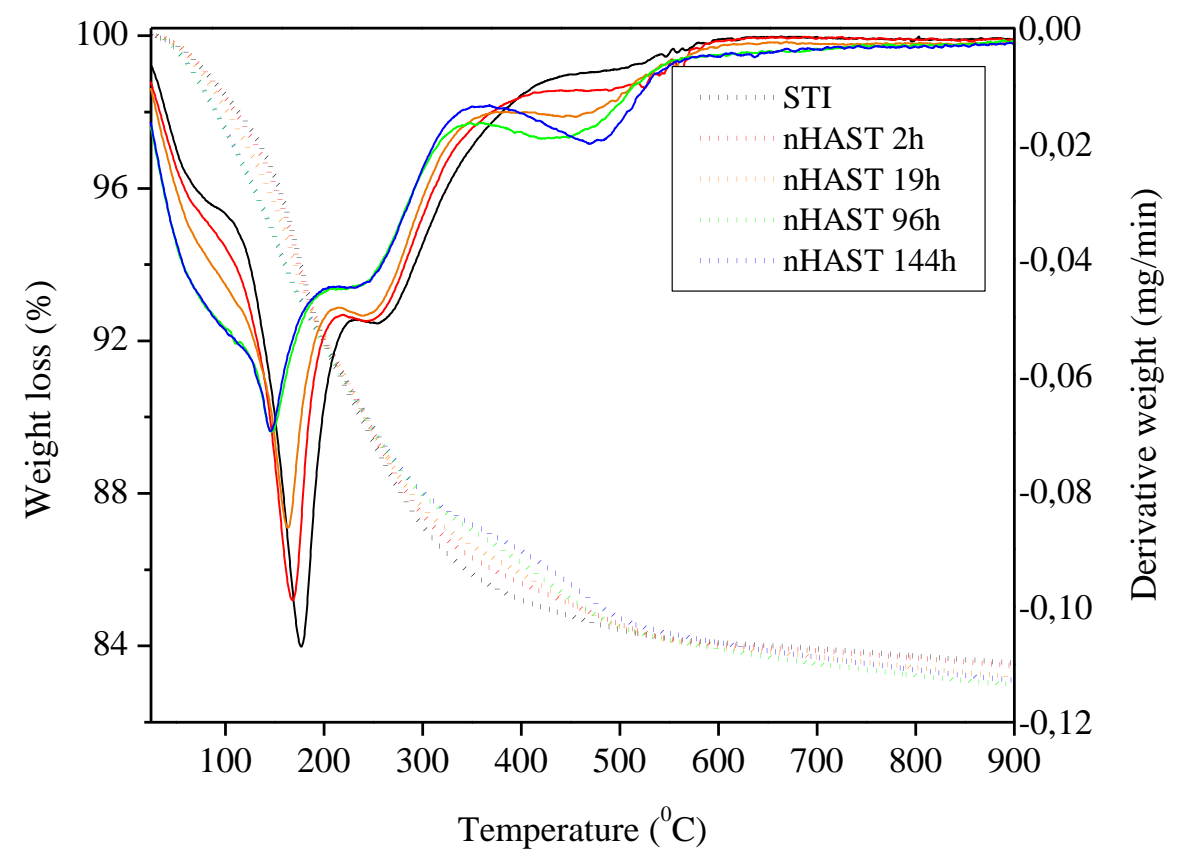


Figure 5: IR-ATR spectra of STI and nHAST composites as a function of crystallization time. Blue arrows indicate $\mathrm{PO}_{4}{ }^{3-}$ bands and black arrow $\mathrm{NH}_{4}{ }^{+}$bands.

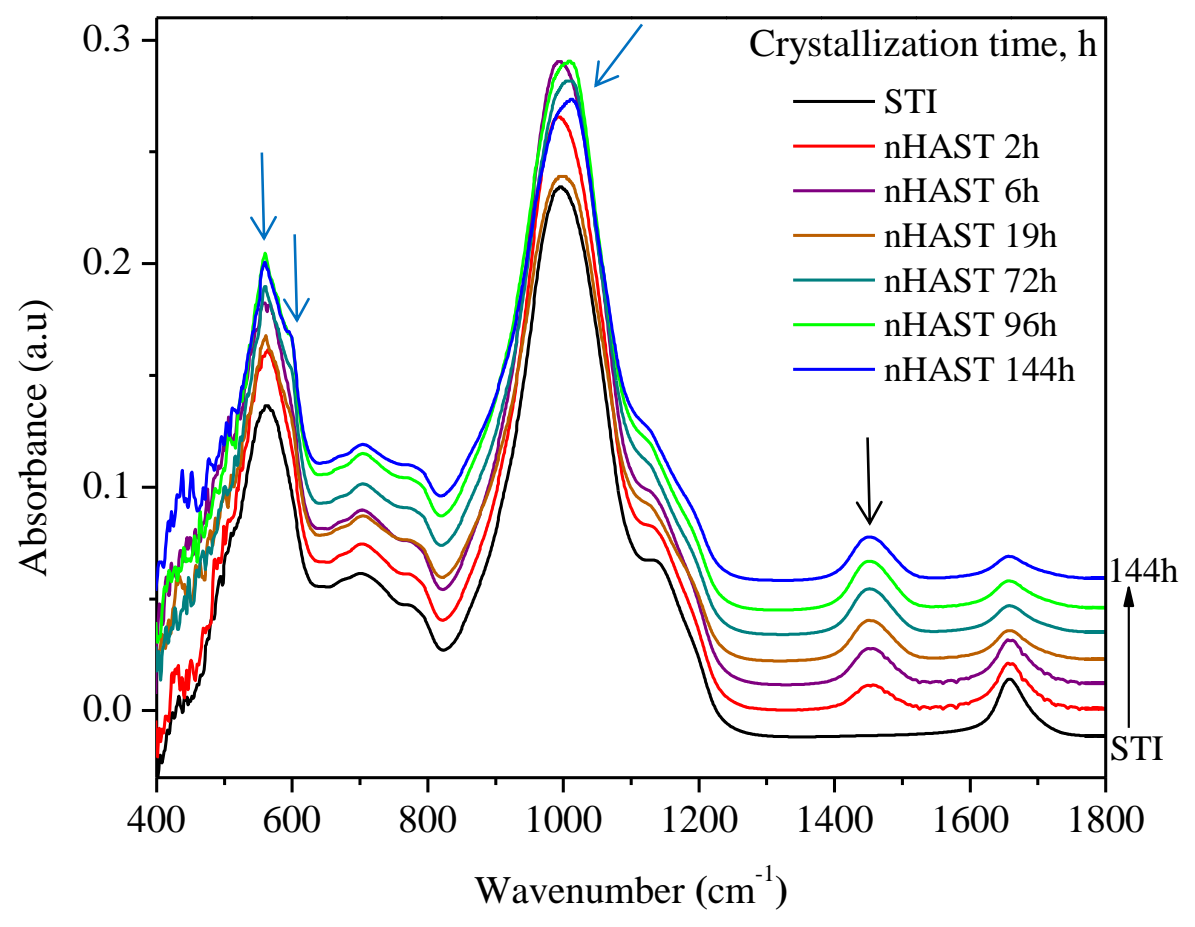


Figure 6: Left: percentage of HAp (as determined from the P content, black line), total defluoridation capacity (in mg/g, red line), and intrinsic HAp defluoridation capacity (in mg/g of HAp, blue line) as a function of the crystallization time. Right: Intrinsic HAp defluoridation capacity as a function of the amount of HAp grown on the STI zeolite surface.
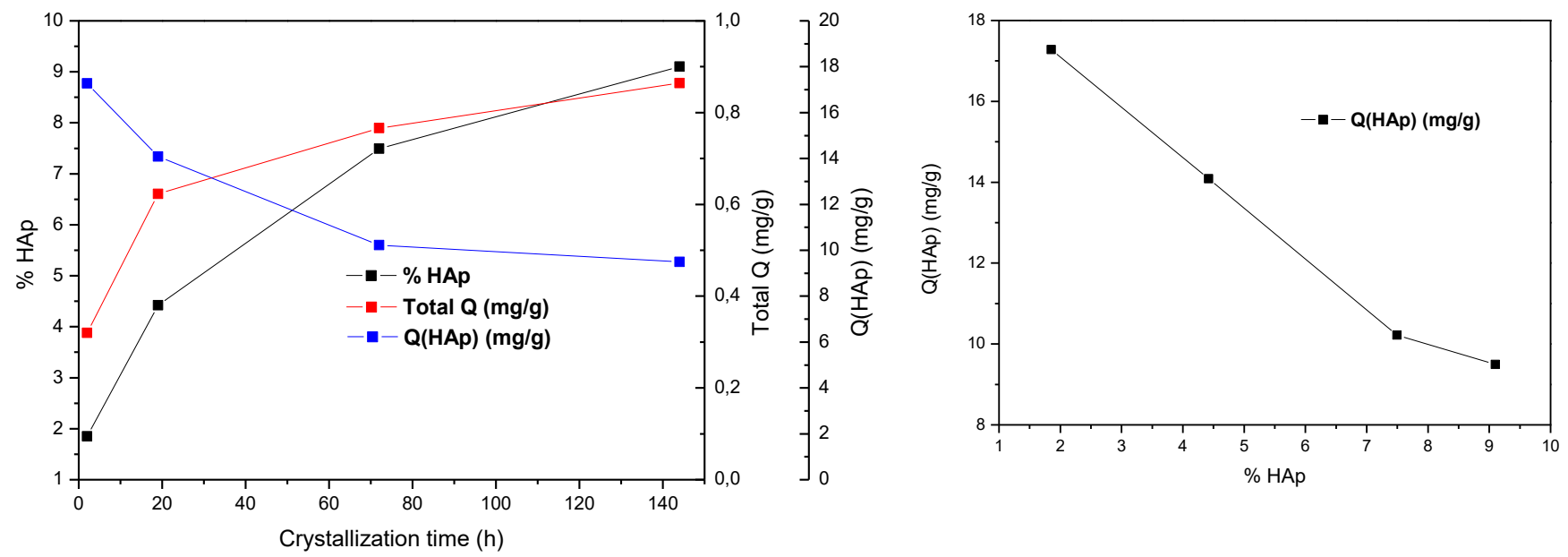
Figure 7: ${ }^{31} \mathrm{P}$ MAS-NMR spectra of nHAST-144h prepared at $\mathrm{pH} 8$ (blue), nHAST-19h prepared at $\mathrm{pH} 8$ (green), nHAST-19h prepared at $\mathrm{pH} 9$ (red line), and a sample of HAp (dotted black line).

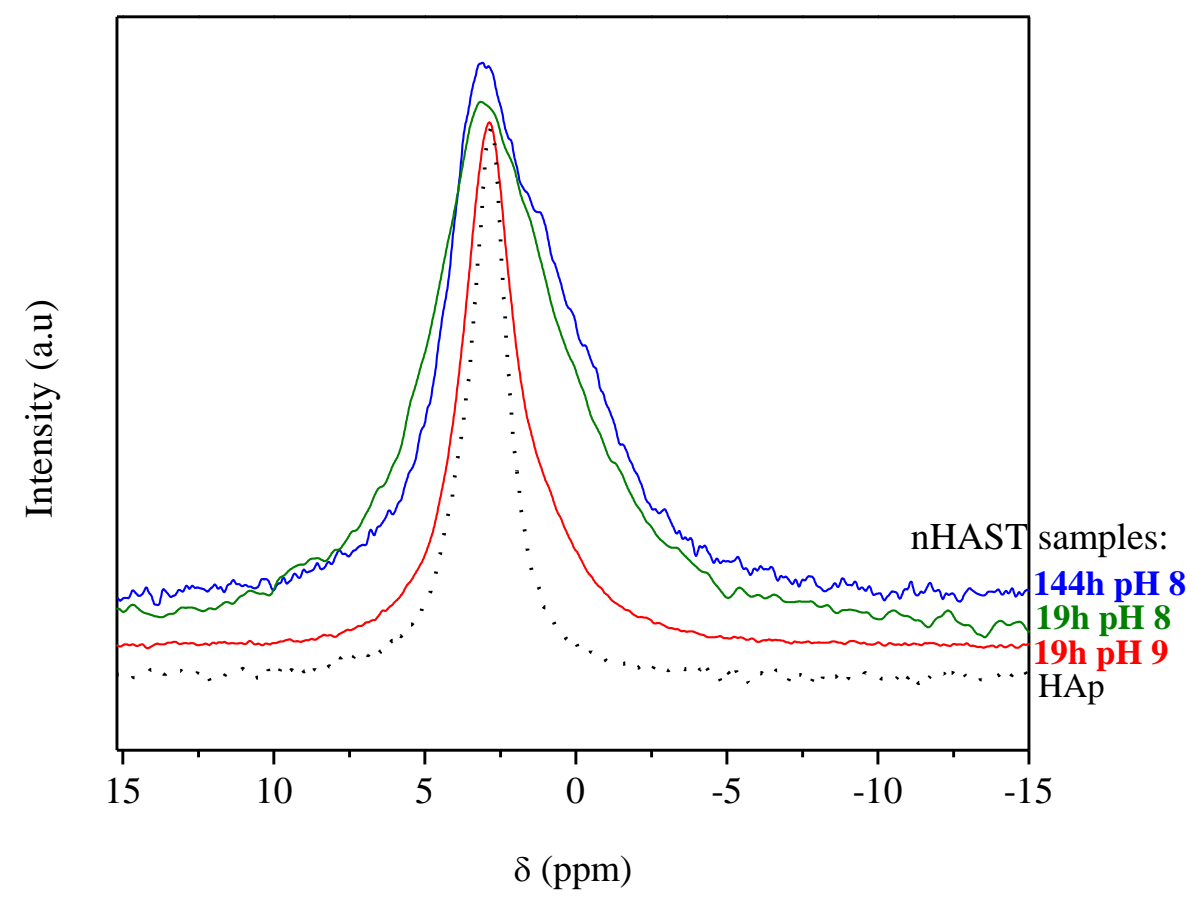


Figure 8: STEM/HAADF/EELS results on nHAST-19h and nHAST-144h composites. a) Lowmagnification image of nHAST-19h. b) Closer observation of the layered materials, where the structure can be distinguished (inset). c) Low-magnification image of nHAST-144h. d) Magnified region where the Spectrum imaging was performed (dashed rectangle). e) Chemical map extracted from the Si (red) and P signals (blue) with the correspondent EELS spectra of the regions denoted as 1 and 2.
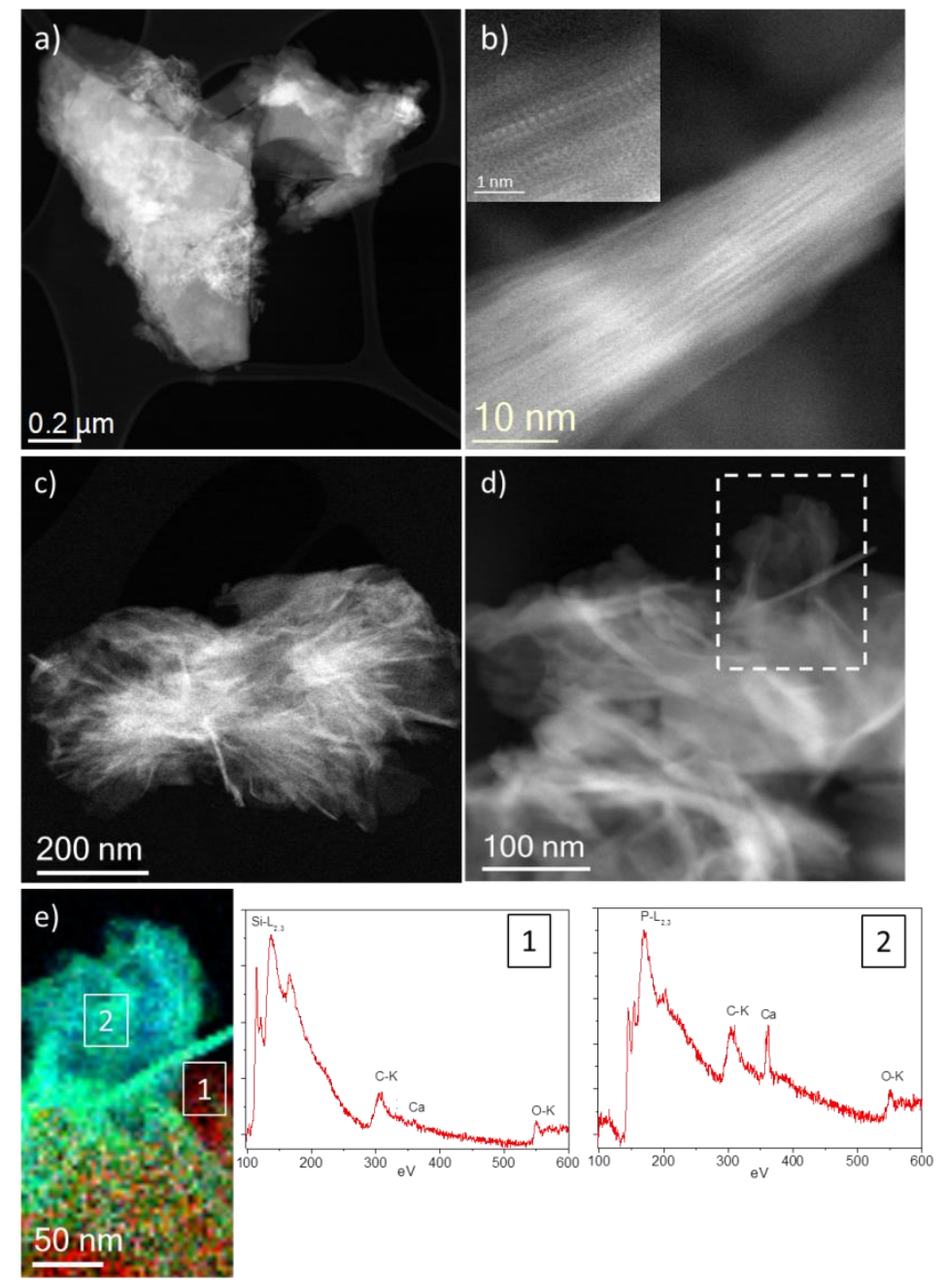
Figure 9: The effect of adsorbent dose on fluoride-removal efficiency (dotted lines) and fluoride equilibrium concentrations (solid lines) by nHAST-144h composite.

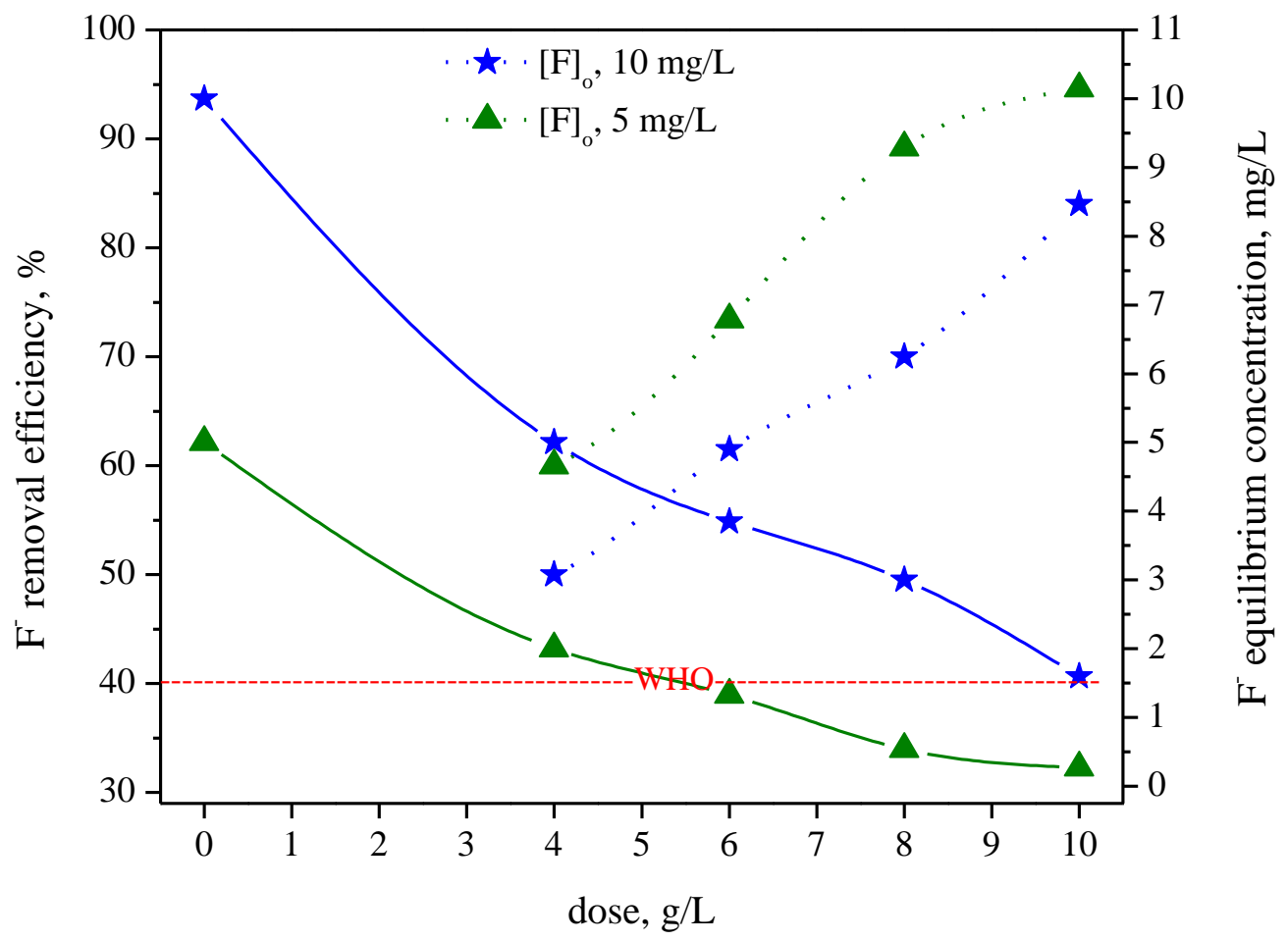


Figure 10: A) Fluoride removal efficiency as a function of contact time of nHAST-144h composite $\left(\mathrm{C}_{\mathrm{o}}=10 \mathrm{mg} / \mathrm{L}\right)$. B) Effect of initial fluoride concentration on the nHAST fluorideremoval capacity (contact time of 20 hours). C) Effect of water $\mathrm{pH}$ on fluoride removal of nHAST composite $\left(\mathrm{C}_{\mathrm{o}}=10 \mathrm{mg} / \mathrm{L}\right.$ and contact time of 20 hours). D) Effect of coexisting ions on fluoride removal of nHAST composite $\left(\mathrm{C}_{\mathrm{o}}=10 \mathrm{mg} / \mathrm{L}\right.$ and contact time of 20 hours $)$. All studies were performed with a dose of $10 \mathrm{~g} / \mathrm{L}$ and at room temperature.
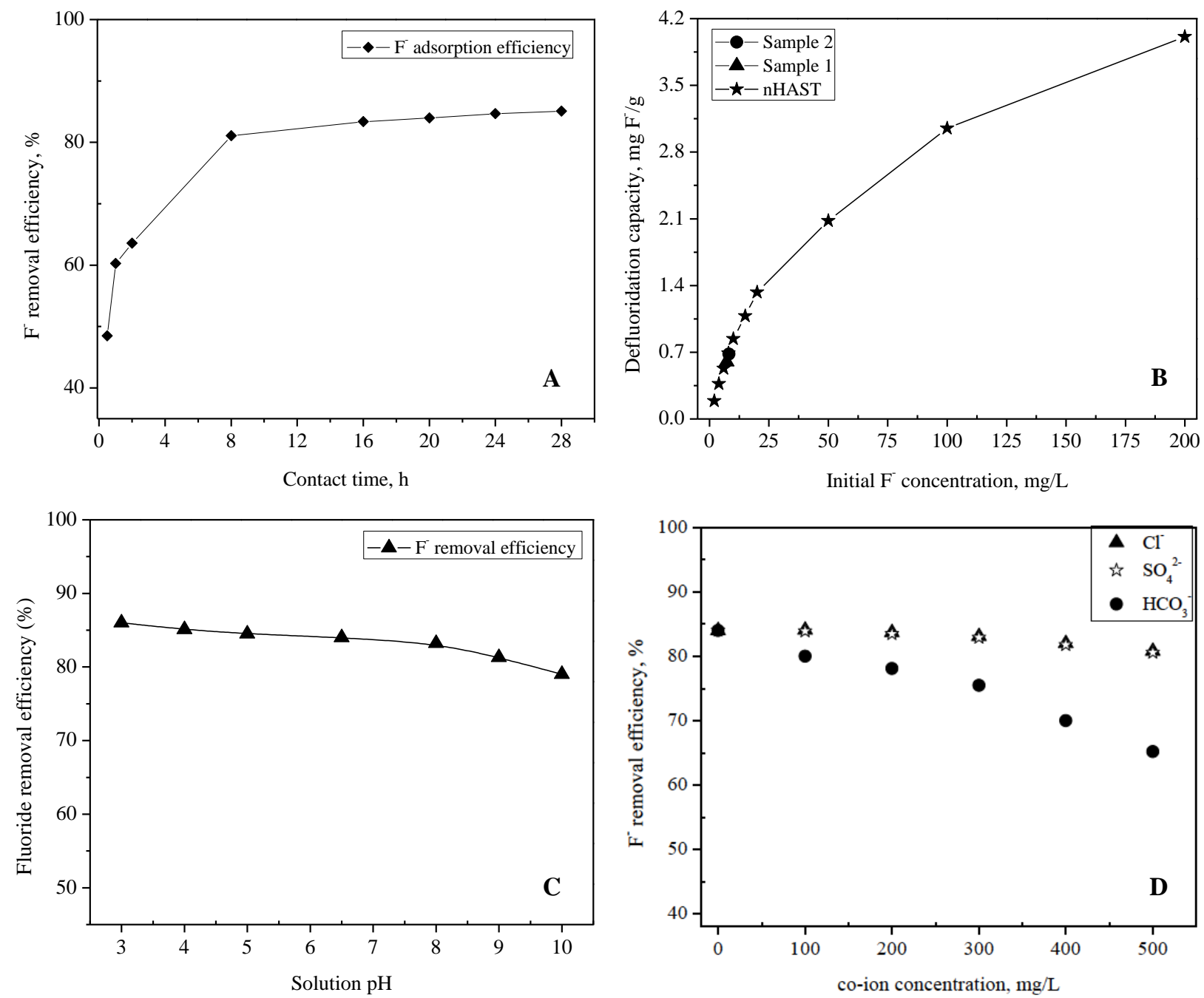